\title{
Estimativa da erosão hídrica do solo pelo modelo Water Erosion Prediction Project na Sub-Bacia do Córrego do Gigante, sul de Minas Gerais
}

\author{
Estimated water soil erosion by the Water Erosion Prediction Project model \\ in the Gigante Stream Basin, Minas Gerais, Brazil \\ Adriano Mota Ferreira** (), Antônio Marciano da Silva ${ }^{1}$, Cláudio André dos Passos ${ }^{1}{ }^{\circledR}$, \\ César Henrique Valentino' ${ }^{(0)}$, Flávio Aparecido Gonçalves' ${ }^{10}$, \\ Paulo Henrique Bretanha Junker Menezes ${ }^{1}$ (])
}

\section{RESUMO}

Objetivou-se, no presente trabalho, monitorar e identificar precipitações erosivas e as perdas de solo (PSs) por meio de parcelas experimentais instaladas na SubBacia do Córrego do Gigante, calibrar o modelo Water Erosion Prediction Project (WEPP) em sua versão encosta, tendo como base os resultados obtidos nas parcelas, e aplicá-lo na área da sub-bacia, para estimativa das PSs por erosão hídrica. O regime pluvial no período de estudo apresentou elevado grau de erosividade e de concentração, pois 57,3\% dos eventos foram erosivos, dos quais, os quatro de maior magnitude, participaram com 47,2\% da erosividade anual. As áreas contempladas pelas interações entre classe de solo, declividade (D) e uso de solo, nas parcelas experimentais, totalizaram 174,32 ha (50\% da área da sub-bacia), cujos valores obtidos resultaram em PS média ponderada de 0,623t ha' ${ }^{-1}{ }^{-1}$, e foram referência no ajuste do modelo WEPP na versão encosta, com estimativa de 0,651 tha' ano'. A aplicação do modelo sobre uma superfície com 93,0\% de abrangência da sub-bacia resultou em uma estimativa de 0,802 t ha ${ }^{-1}$ ano $^{-1}$ para a taxa de PS. As áreas de solo exposto, embora participando com apenas 7,9\% da área da sub-bacia, produziram 85,1\% das PSs estimadas, o que, por outro lado, reflete a influência positiva da cobertura vegetal na diminuição da erosão hídrica. Simulando a implantação de cobertura sob a forma de campo/ pastagem e/ou reflorestamento, nas áreas de solo descoberto, as taxas de PS na sub-bacia reduziriam significativamente para 0,215 t ha" ano"1.

Palavras-chave: modelagem de perdas de solo; parcelas de monitoramento; precipitações erosivas.

\begin{abstract}
The objective of the present work was to monitor and identify erosive precipitations and monitor soil losses through experimental plots installed in the Córrego do Gigante sub-basin, to calibrate the Water Erosion Prediction Project (WEPP) model, in its slope version, based on the results obtained in the plots, and apply it to the sub-basin area to estimate soil losses due to water erosion. The rainfall regime during the study period showed high degrees of erosivity and concentration, since $57 \%$ of the events were erosive, of which, the four most erosive events corresponded to $47.2 \%$ of the annual erosivity. The areas covered by the interactions between soil class, slope, and land use, in the experimental plots, totaled 174.32 ha (50\% of the sub-basin area), whose values obtained resulted in a weighted average loss of $0.623 \mathrm{t}$ ha' ${ }^{-1}$ year', which were a reference in the adjustment of the WEPP model in the hillside version, with an estimate of $0.651 \mathrm{t} \mathrm{ha}^{-1}$ year-1. The application of the model on a surface with 93.0\% coverage of the sub-basin resulted in an estimate of $0.802 \mathrm{t} \mathrm{ha}^{-1}$ year ${ }^{-1}$ for the soil loss rate. The exposed soil areas, although accounting for only $7.9 \%$ of the sub-basin area, produced $85.1 \%$ of the estimated soil losses, which, on the other hand, reflects the positive influence of vegetation cover in the decrease of water erosion. Simulating the implementation of cover in the form of field/pasture and/or reforestation in the areas of bare soil significantly reduced the rates of soil losses in the sub-basin to 0.215 t ha" year
\end{abstract}

Keywords: soil loss modeling; experimental plots; erosive rainfall.

\section{INTRODUÇÃO}

A erosão hídrica é considerada um dos maiores problemas ambientais em todo o mundo, influenciando tanto os solos agrícolas quanto os florestais (HU; FLANAGAN, 2013), e pode ser contextualizada como o processo de desgaste da superfície terrestre pela ação da água, que destaca e remove o solo, ou seu material geológico de origem, de um ponto da superfície e o deposita em outro (SOIL SCIENCE SOCIETY OF AMERICA, 2008).

A erosão hídrica do solo está associada aos efeitos da erosividade das chuvas e à erodibilidade dos solos, em que os principais fatores estão relacionados

IInstituto de Ciência e Tecnologia, Universidade Federal de Alfenas - Poços de Caldas (MG), Brasil.

*Autor correspondente: adrianomotaferreira@gmail.com

Conflitos de interesse: os autores declaram não haver conflito de interesses.

Financiamento: Fundação de Amparo à Pesquisa do Estado de Minas Gerais (FAPEMIG) - processo CAG APQ-O0889-15; Conselho Nacional de Desenvolvimento Científico e Tecnológico (CNPq) - processo 312282/2014-1 Bolsa Produtividade e Grants Associado; Coordenação de Aperfeiçoamento de Pessoal de Nível Superior (CAPES).

Recebido: 23/07/2019 - Aceito: 21/04/2O2O - Reg. ABES: 20190216 
às suas características físicas, à topografia e ao uso do solo, como, por exemplo, tipo de cobertura vegetal, práticas de manejo e conservação (WISCHMEIER; SMITH, 1978).

Entre os efeitos ocasionados pela erosão hídrica está a redução dos teores de matéria orgânica e dos nutrientes do solo, assim como a degradação de sua estrutura (DOTTERWEICH, 2013; PRUSKI, 2013; CÂNDIDO et al., 2014). Ressaltam-se, ainda, problemas ocasionados nos cursos d'água e nos reservatórios em consequência dos processos erosivos, associados ao assoreamento, à poluição e à eutrofização das águas superficiais, prejuízo na quantidade e qualidade dos recursos hídricos, podendo ainda tornar grandes áreas improdutivas ou economicamente inviáveis (HIGGIT, 1991; BARROSO; SILVA, 1992; BATISTA, 2016).

A Food and Agricultural Organization (FAO), em 2015, publicou em seu relatório Status of the world's soil resources: main report que as perdas por erosão hídrica alcançaram de 20 a $30 \mathrm{Gt}^{-1} \mathrm{ano}^{-1}$ e acrescenta ainda que, diante da gravidade do processo, existe a necessidade de estabelecimento de limiares entre níveis aceitáveis, ou não, de erosão (FAO, 2019). Nesse sentido, utiliza-se a tolerância de perdas de solo, definida por Wischmeier e Smith (1978) como a quantidade de solo que pode ser perdida por erosão, sendo mantidos seus níveis de fertilidade e produtividade, por um longo período. Li et al. (2009) destacam que os estudos acerca de tolerância de perda de solo são baseados principalmente na taxa de formação do solo, o que dificulta sua mensuração, pois são inúmeros os fatores de formação, como, por exemplo, material de origem, relevo, clima, tempo e microrganismos (ALEXANDER, 1988).

Torna-se, assim, de extrema importância a quantificação da erosão, para determinar seu impacto ambiental, podendo ser realizada por intermédio da medição direta em parcelas instaladas em campo e da modelagem do processo, para o desenvolvimento de avaliações confiáveis de predições de perdas de solo, fator essencial para a gestão de programas e técnicas voltados ao controle da erosão do solo e ao planejamento do seu uso e sua ocupação de forma sustentável (TOY; FOSTER; RENARD, 2002; DEMARCHI; ZIMBACK, 2014).

Pode-se, por exemplo, prever os impactos antes mesmo de determinada cultura ou prática agrícola ser adotada, consistindo a modelagem em uma ferramenta importante ao suporte de decisão, uma vez que as alternativas de manejo são numerosas e, muitas vezes, de alto custo e também seus resultados são lentos, levando anos ou décadas para se mensurar seus impactos na erosão (CHAVES, 1996; STROOSNIJDER, 2005).

O desenvolvimento de modelos preditores de erosão hídrica tem recebido grande atenção por parte de cientistas, devido às dificuldades de medições diretas da erosão em campo (BATISTA, 2016). Dentre eles, um dos mais utilizados é o Water Erosion Prediction Project (WEPP). Segundo Laflen, Lane e Foster (1991) e USDA (1995), o modelo WEPP, baseado nos princípios físicos do processo de erosão, é um pacote tecnológico para estimativas das perdas de solo desenvolvido em parceria entre as instituições Agricultural Research Service, Soil Conservation Service, Forest Service in the Departament of Agriculture e Bureau of Land Management in the US Department of the Interior, nos Estados Unidos. O WEPP, portanto, pode subsidiar o planejamento ambiental e a conservação da água e do solo, permitindo a predição dos impactos resultantes de práticas de manejo de terras usadas para produção agrícola, pastagens e áreas florestais na erosão (AMORIM, 2003).

Lane et al. (1992) explicam que o WEPP é um modelo de simulação dinâmico que incorpora os conceitos de erosão entressulcos e nos sulcos. Permite simular os processos que ocorrem em determinada área em função do estado atual do solo, da cobertura vegetal, dos restos de cultura e da umidade do solo. Para cada passo de processamento diário, as características do solo e da cobertura vegetal são atualizadas. Quando ocorre precipitação, baseando-se nas características atuais do terreno, pode-se determinar se haverá escoamento superficial. Havendo, o modelo estima o desprendimento, o transporte e a deposição de partículas ao longo da encosta, porém o modelo não atua na parte de erosão em grandes voçorocas e cursos d'água perenes.

O WEPP é apresentado em três versões: encosta, malha e bacia hidrográfica. A versão para encosta é uma substituição direta da Universal Soil Loss Equation (USLE), acrescentando-se a capacidade de estimar a deposição de sedimentos ao longo do terreno. A versão para bacias hidrográficas possibilita a determinação do desprendimento, do transporte e da deposição de sedimentos ao longo das diversas encostas até os cursos d'água. A versão malha é aplicável para áreas nas quais os limites não coincidem com os limites da bacia hidrográfica. Para atender às três versões, o modelo WEPP é dividido em diversos componentes, que contemplam a parametrização dos processos que regulam o fenômeno erosivo (PRUSKI, 2013).

Diante do exposto, objetivou-se, no presente trabalho, monitorar e caracterizar as precipitações erosivas, monitorar as perdas de solo por meio de parcelas experimentais instaladas na sub-bacia em estudo e, por fim, calibrar e aplicar o modelo WEPP em sua versão encosta, tendo por base os dados monitorados em campo, para estimativa das perdas de solo por erosão hídrica. A área estudada é a Sub-Bacia Hidrográfica do Córrego do Gigante, que é um tributário do Ribeirão do Cipó, de importância na região pelo uso de seus mananciais para três atividades das mais relevantes no contexto econômico e dos recursos hídricos do município de Poços de Caldas, Minas Gerais: abastecimento público ( $47 \%$ do consumo), geração de energia (reservatório que regulariza vazão a jusante) e mineração.

\section{Caracterização da área de estudo}

A área de estudo compreende a Sub-Bacia Hidrográfica do Córrego do Gigante, com área de drenagem de $3,67 \mathrm{~km}^{2}$, localizada na zona rural do município de Poços de Caldas, no estado de Minas Gerais, nas coordenadas $330200 \mathrm{~W}$ e 7577380 S sistema SIRGAS 2000 - Fuso 23K, como mostrado na Figura 1.

O clima na região é considerado mesotérmico (C), de acordo com a classificação de Köppen, apresentando duas variações, o Cwa e o Cwb, predominando-se o Cwb. Quanto à temperatura, a média do mês mais frio é inferior a $18^{\circ} \mathrm{C}$ e a do mês mais quente ultrapassa $22^{\circ} \mathrm{C}$. A estação seca ocorre entre meados de abril e início de setembro, sendo julho o mês de menor índice pluviométrico. $\mathrm{O}$ índice pluviométrico varia entre 1.100 e $1.700 \mathrm{~mm}$, sendo o período entre janeiro e fevereiro o mais chuvoso (MORAES, 2007).

De acordo com Ellert (1959), na região onde se insere a Sub-Bacia Hidrográfica do Córrego do Gigante ocorrem quatro tipos de litologia, sendo:

- rochas efusivas e hipoabissais (tinguaítos e fonólitos);

- rochas plutônicas (nefelina sienitos, lujauritos e chibinitos);

- brechas, tufos e conglomerados;

- rochas potássicas (associadas a processos metassomáticos).

A região se destaca, também, pelo intenso fraturamento e pela hidrografia fortemente controlada pela litologia e pelo sistema de fraturas (TINÓS et al., 2014).

Dentre as feições geomorfológicas da Região Sudeste do Brasil, o Planalto de Poços de Caldas situa-se na província geomorfológica do Planalto Atlântico 
e na zona do Planalto Sul de Minas Gerais. Essa zona é subdividida em três subzonas: a Superfície do Alto Rio Grande; o Planalto de São Pedro de Caldas; e o próprio Planalto de Poços de Caldas (TINÓS et al., 2014). De acordo com Moraes e Jiménez-Rueda (2008), a análise dos processos morfogenéticos indicou a presença de dois grandes grupos de paisagens no Planalto de Poços de Caldas: as planálticas e as aluviais.

De acordo com o Mapa de Solos do Estado de Minas Gerais (UFV et al., 2010), os solos da região do Planalto de Poços de Caldas são classificados como Latossolo Vermelho-Amarelo (LVA) distrófico, Cambissolo Háplico (CX) Tb distrófico e Neossolo Litólico distrófico. As classes de solo mais abrangentes na área da sub-bacia são LVA e CX, com representatividade de 57,6 e 36,7\%, respectivamente, sendo os 5,7\% restantes representados pelos solos indiscriminados de várzea (SIV).

Já quanto ao uso do solo, $47,7 \%$ da área contempla campo/pastagem, $26,2 \%$, mata nativa, $16,2 \%$, reflorestamento e $7,9 \%$, solo exposto. O restante da área distribui-se entre espelhos d'água, campos associados à umidade e às culturas, com participações de 2,0\% da área.

As classes de declividades foram consideradas de acordo com recomendação da Embrapa (2006) e suas áreas de ocorrências estão apresentadas na Figura 2.

\section{METODOLOGIA}

\section{Precipitações erosivas}

Os dados de precipitação, registrados no pluviógrafo em intervalos de cinco minutos e armazenados no datalogger da Estação Hidrossedimentométrica da
Sub-Bacia Hidrográfica do Córrego do Gigante, foram utilizados para a estimativa da erosividade de cada evento isolado de chuva, assim considerados aqueles separados entre si por mais de seis horas, os quais foram caracterizados como erosivos os que atenderam ao proposto por De Maria (1994). A estimativa da

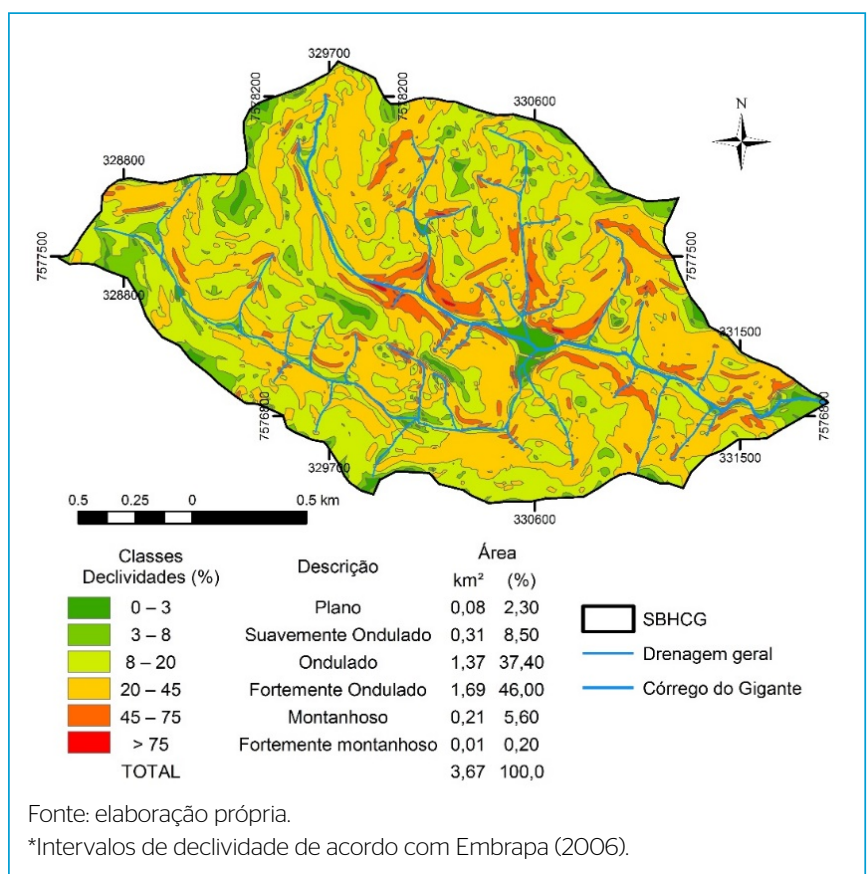

Figura 2 - Classes de declividades e suas áreas de ocorrências na Sub-Bacia do Córrego do Gigante*.

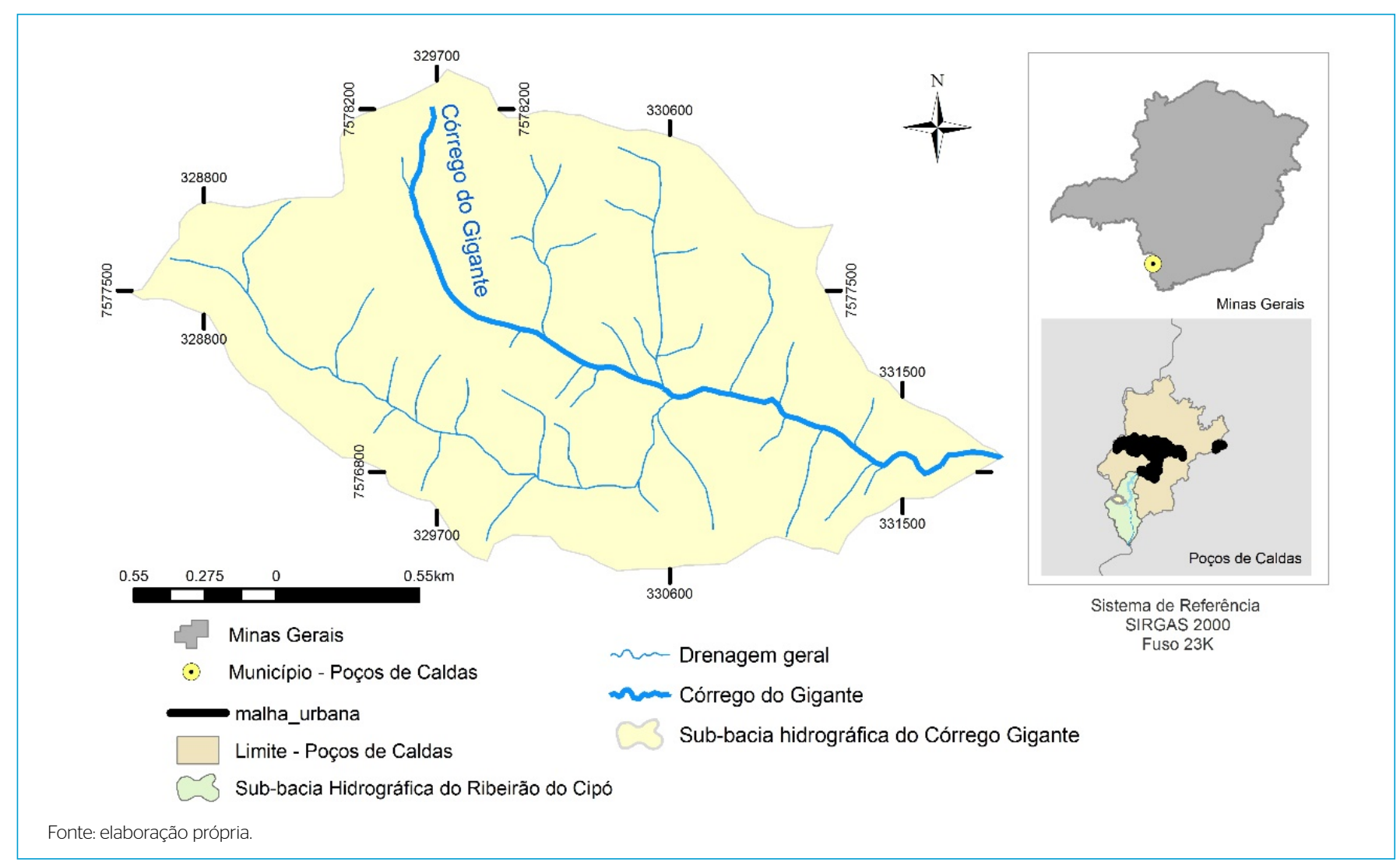

Figura 1 - Localização da Sub-Bacia Hidrográfica do Córrego do Gigante. 
erosividade da chuva requer o conhecimento de sua energia cinética, a qual foi estimada pela aplicação de dois modelos matemáticos, o primeiro, desenvolvido por Wischmeier e Smith (1978) e modificado por Foster et al. (1981), cujos coeficientes foram ajustados para o Sistema Internacional, Equação 1, e o segundo, desenvolvido por Wagner e Massambani (1988), Equação 2:

$\mathrm{Ec}=0,119+0,0873 \cdot \log _{10}(\mathrm{I})$

$\mathrm{Ec}=0,153+0,0645 . \log _{10}(\mathrm{I})$

Em que:

$\mathrm{Ec}=$ energia cinética por $\mathrm{mm}$ de precipitação expressa em $\mathrm{MJ} \mathrm{ha}^{-1} \mathrm{~mm}^{-1}$; $\mathrm{I}=$ a intensidade média da chuva $\mathrm{em} \mathrm{mm} \mathrm{h}^{-1}$.

Destaca-se que a Equação 1 é amplamente utilizada no meio científico internacional e no Brasil, tendo sido bem avaliada por Ramon et al. (2017). Já entre a Equação 1 e 2, Gonçalves et al. (2006) destacam não haver diferença expressiva no cálculo da energia cinética. A energia cinética total do evento (Ect) foi calculada pela Equação 3:

$\mathrm{Ect}=\mathrm{Ech}$

Em que: Ect é expressa em MJ ha-1; e h, que é a lâmina total precipitada no evento, expressada em $\mathrm{mm}$.

A erosividade propriamente dita, expressa pelo $\mathrm{EI}_{30}$, foi calculada conforme Equação 4:

$\mathrm{EI}_{30}=\mathrm{Ect} \mathrm{I}_{30}$

Em que:

$\mathrm{EI}_{30}=$ a erosividade da chuva em MJ mm ha- ${ }^{-1} \mathrm{~h}^{-1}$;

$\mathrm{I}_{30}=\mathrm{a}$ intensidade média máxima em 30 minutos consecutivos, em $\mathrm{mm} \mathrm{h}^{-1}$, do evento de precipitação.

\section{Parcelas experimentais de perda de solo e água}

Foram instaladas parcelas experimentais na área de estudo, considerando-se as associações entre classes de solo, uso do solo e declividades. As classes de declividade contempladas foram ondulado e fortemente ondulado, que, em conjunto, ocorrem em 83,4\% da Sub-Bacia Hidrográfica do Córrego do Gigante, sendo que as declividades efetivas de cada parcela instalada, assim como as combinações contempladas entre as classes de solo e seus usos, além das respectivas áreas de abrangência, constam na Tabela 1.

Na Figura 3 é apresentado um croqui das parcelas de monitoramento das perdas de solo (erosão hídrica) e vista de uma parcela instalada em campo, cuja área é de $10 \mathrm{~m}^{2}$. As caixas coletoras dos deflúvios, com volume útil de $40 \mathrm{~L}$, foram previamente calibradas em laboratório, obtendo-se, para cada uma, a equação que relaciona nível d'água $(\mathrm{cm})$ e volume $(\mathrm{L})$.

As caixas foram interligadas por uma canaleta que coleta 1/9 do volume de água (enxurrada) excedente da primeira caixa, que tem na sua saída um divisor do tipo Geib com nove aberturas. A primeira caixa tem capacidade para coletar no máximo $40 \mathrm{~L}$, o que corresponde a um deflúvio de $4 \mathrm{~mm}$, já a segunda tem capacidade de coletar um volume de $80 \mathrm{~L}$, o que corresponderia a uma lâmina de $8 \mathrm{~mm}$, porém, como esse volume corresponde a 1/9 do volume drenado da primeira caixa, efetivamente, o deflúvio é de $72 \mathrm{~mm}$ e, no conjunto, o deflúvio máximo coletável foi de $76 \mathrm{~mm}$.

A cada campanha realizada (em intervalos semanais no período chuvoso e quinzenais no período seco) eram quantificados a precipitação coletada no pluviômetro, o deflúvio ocorrido (volumes coletados nas caixas 2 e 3, pela leitura da escala graduada, fixada na parede interna de cada caixa), a homogeneização do volume contido nas caixas (com o uso de uma pá de madeira) e a coleta em duplicata de amostra contendo $200 \mathrm{~mL}$ de água e sedimentos em cada caixa, em frasco de vidro com tampa, previamente secos e pesados, para posterior condução ao laboratório para quantificação do material sólido em suspensão.

$\mathrm{Na}$ fase laboratorial, as amostras foram separadas para decantação, por 48 horas, para posterior redução de volume com pipeta de $25 \mathrm{~mL}$. Feita a redução, o material restante foi levado à estufa em temperatura de $60^{\circ} \mathrm{C}$ por 48 horas, visando à evaporação e à secagem, para quantificação de sedimento seco.

Tabela 1 - Caracterização das parcelas em função das associações entre classes de solo, uso do solo e classes de declividade e respectivas áreas de ocorrência na Sub-Bacia do Córrego do Gigante.

\begin{tabular}{|c|c|c|c|c|c|}
\hline Parcela & Classes de solo & Uso do solo & Classes de declividade (\%) & Declividade medida (\%)* & Área de abrangência (ha) \\
\hline 1 & $C X$ & Solo exposto & $8-20$ & 12 & 2,86 \\
\hline 2 & $C X$ & Campo/pastagem & $8-20$ & 12 & \multirow{2}{*}{11,58} \\
\hline 3 & $C X$ & Campo/Pastagem & $8-20$ & 18 & \\
\hline 4 & $C X$ & Mata nativa & $20-45$ & 28 & \multirow{2}{*}{33,06} \\
\hline 5 & $C X$ & Mata nativa & $20-45$ & 22 & \\
\hline 6 & LVA & Solo exposto & $8-20$ & 12 & 10,98 \\
\hline 7 & LVA & Mata nativa & $20-45$ & 28 & \multirow{2}{*}{32,91} \\
\hline 8 & LVA & Mata nativa & $20-45$ & 26 & \\
\hline 9 & LVA & Campo/pastagem & $20-45$ & 23 & 34,42 \\
\hline 10 & LVA & Campo/pastagem & $8-20$ & 18 & 48,51 \\
\hline Total & - & - & - & - & 174,32 \\
\hline
\end{tabular}

CX: Cambissolo Háplico; LVA: Latossolo Vermelho-Amarelo; *valores obtidos no local de instalação das parcelas (\%).

Fonte: elaboração própria. 


\section{Modelo Water Erosion Prediction Project}

Inicialmente foram identificadas as informações necessárias para elaboração do banco de dados requerido pelo modelo, uma vez que o disponibilizado se refere, exclusivamente, aos dados da América do Norte. O primeiro grupo de informações organizadas diz respeito aos solos (Tabela 2), neste caso, o LVA e o CX, presentes na área de estudo. Os dados de areia, silte, argila, matéria orgânica, classe textural e capacidade de troca catiônica foram extraídos de Amorim (2003), Gonçalves (2008), Pereira et al. (2010), Melo Neto (2012) e Purcino (2017).

Os valores de condutividade hidráulica efetiva $(\mathrm{Ke})$ utilizados, foram estimados por Reis (2017) e variaram entre 0,42 e $10,84 \mathrm{~mm} \mathrm{~h}^{-1}$, com média ponderada de $2,08 \mathrm{~mm} \mathrm{~h}^{-1}$, valor utilizado para o ajuste do modelo. Os parâmetros erodibilidade entressulcos e em sulcos e tensão crítica de cisalhamento dos solos foram estimados por equações de rotina do modelo WEPP, como descrito por Flanagan e Nearing (1995).

Posteriormente, trabalhou-se com as informações de entrada referentes ao uso e manejo do solo, como crescimento de plantas, condições iniciais, decomposição de resíduos e práticas de manejo do solo. Os dados foram obtidos com base nas condições locais e complementados com informações do banco de dados do próprio modelo. Foram editados e criados os arquivos de extensão própria do modelo para que melhor representassem as características da área de estudo, em consonância com o uso do solo. Para a criação dos arquivos climáticos do modelo WEPP, a interface conta com o gerador climático Command - Line Interface Generator (CLIGEN), com cerca de 2.600 parâmetros, estes associados aos Estados Unidos da América. Neste caso, foi necessário criar o arquivo do modelo, com os dados observados, obtidos da própria estação instalada na Sub-Bacia Hidrográfica do Córrego do Gigante, com registro diário durante o período de 05 de outubro de 2017 a 30 de setembro de 2018, que possibilitou gerar a série de dados sintéticos com o simulador CLIGEN 5.x.

Para realização da calibração do modelo, foram criados os arquivos de encostas propostos, sendo que os comprimentos de rampa foram os mesmos de cada parcela $(4 \mathrm{~m})$ e as declividades das rampas, as mesmas apresentadas na Tabela 1 para cada uma das parcelas experimentais, com as combinações, a classe de solo e as classes de uso.
Por fim, para a aplicação modelo WEPP na simulação das perdas de solo para a área da Sub-Bacia Hidrográfica do Córrego do Gigante, calcularam-se, em Sistema de Informação Geográfica (SIG), para cada classe de solo, em associação com cada tipologia de uso do solo, suas áreas de ocorrência na sub-bacia estudada, para cada classe de declividade, conforme Embrapa (2006), e os respectivos valores médios de declividade, para criação dos arquivos de encosta do modelo. Inicialmente, estimaram-se as perdas em encostas com rampas de $4 \mathrm{~m}$, para cada interação (solo/uso/declividades médias na classe), processo de calibração do modelo, estendendo-se o resultado para a área de ocorrência da referida interação. Posteriormente, aplicou-se o modelo na área da Sub-Bacia Hidrográfica do Córrego do Gigante com a incorporação das classes de declividades não contidas nas interações contempladas e a inclusão do uso reflorestamento, para estimativa das perdas e avalição de dois cenários, em que se considera o uso campo/pastagem e reflorestamento nas áreas de solo descoberto.

Tabela 2 - Valores dos atributos matéria orgânica, argila e areia, utilizados no banco de dados do Water Erosion Prediction Project na representação das parcelas experimentais.

\begin{tabular}{l|c|c|c|c} 
Parcela & Solo & MO (\%) & Argila (\%) & Areia (\%) \\
\hline P1 & CX & 1,68 & 55,91 & 23,69 \\
\hline P2 & CX & 2,52 & 59,52 & 17,46 \\
\hline P3 & CX & 2,48 & 59,79 & 17,19 \\
\hline P4 & CX & 3,47 & 63,26 & 13,67 \\
\hline P5 & CX & 2,59 & 60,59 & 14,92 \\
\hline P6 & LVA & 1,73 & 56,15 & 23,27 \\
\hline P7 & LVA & 2,39 & 60,64 & 15,94 \\
\hline P8 & LVA & 2,35 & 58,75 & 19,31 \\
\hline P9 & LVA & 2,90 & 61,81 & 12,52 \\
\hline P10 & LVA & 2,90 & 62,12 & 12,38 \\
\hline
\end{tabular}

Fonte: Purcino (2017).

MO: matéria orgânica CX: Cambissolo Háplico; LVA: Latossolo Vermelho-Amarelo.

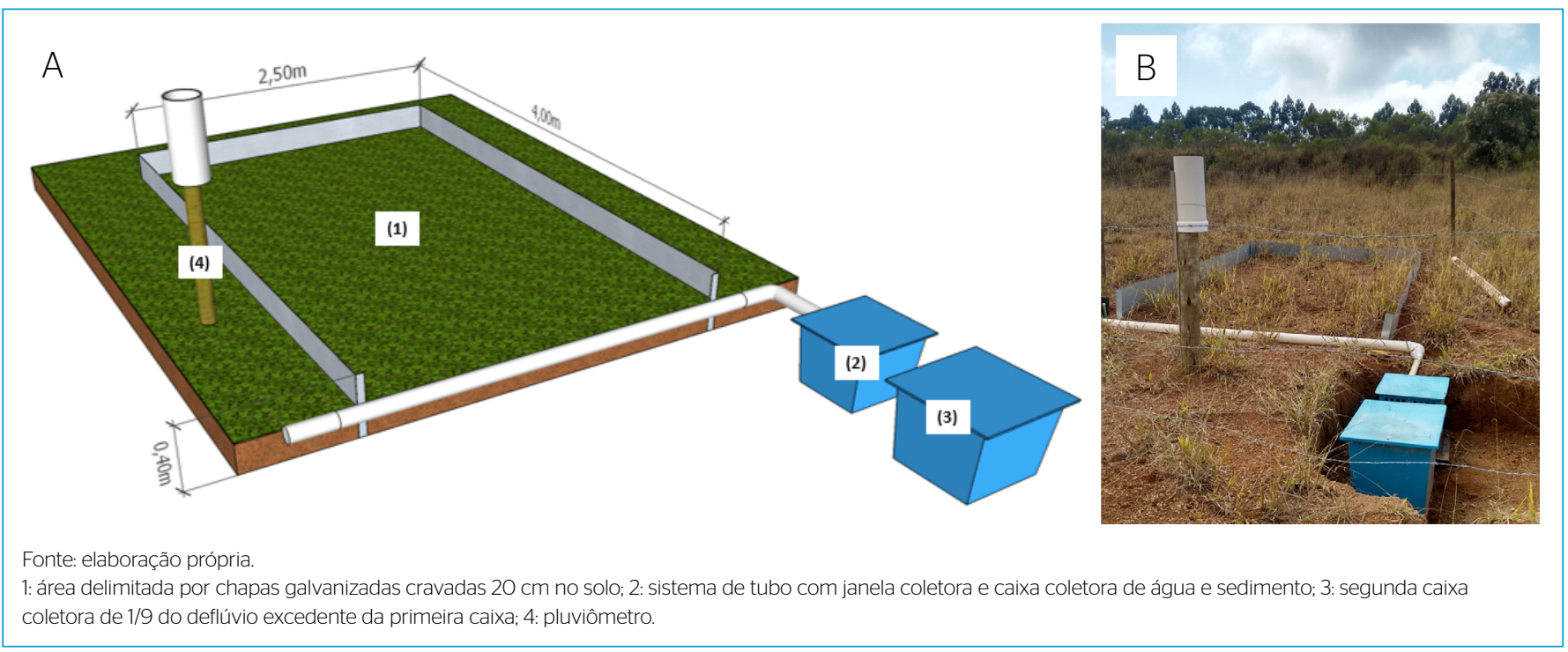

Figura 3 - (A) Croqui de uma parcela de monitoramento da erosão hídrica do solo e (B) vista de uma instalada em campo. 


\section{RESULTADOS E DISCUSSÃO}

\section{Precipitações erosivas}

No período de estudo, compreendido entre 27 de outubro de 2017 e 30 de setembro de 2018, foi registrado um total precipitado de $1.579,6 \mathrm{~mm}$, sendo identificados 30 eventos considerados erosivos, os quais totalizaram $905,0 \mathrm{~mm}$, equivalentes a 57,3\% do total, refletindo, assim, regime de precipitação com elevada concentração de eventos erosivos, o que indica a necessidade de adoção de práticas de conservação de solo na região.

A erosividade das chuvas expressa pelo $\mathrm{EI}_{30}$, com energias cinéticas estimadas pelos métodos de Wischmeier e Smith (1978) e Wagner e Massambani (1988), foi 6.177,7 e 6.554,9 MJ mm ha- ${ }^{-1}{ }^{-1}$, respectivamente. Como referência, podemos citar o trabalho de Mello et al. (2007), que estimaram a erosividade média anual para Minas Gerais encontrando valores entre 5.000 e 12.000 MJ mm $\mathrm{ha}^{-1} \mathrm{~h}^{-1}$, associados à precipitação média anual oscilando entre 800 e $1700 \mathrm{~mm}$. Ainda de acordo com os autores, o valor estimado para Sub-Bacia Hidrográfica do Córrego do Gigante enquadra-se como de erosividade média a alta, como os estimados para o sul de Minas entre 4.905 e $7.357 \mathrm{MJ} \mathrm{mm} \mathrm{ha}^{-1} \mathrm{~h}^{-1}$, ratificando a consistência dos valores calculados.

Outros indicadores que sinalizam elevados graus de erosividade e de concentração do regime pluvial foram identificados entre os eventos caracterizados como erosivos, como o de maior expressão, que contabilizou um total de $89 \mathrm{~mm}$, intensidade média de $19,6 \mathrm{~mm} \mathrm{~h}^{-1}$ e EI $_{30}$ de 1.328,8 e 1.354,9 MJ mm $\mathrm{ha}^{-1} \mathrm{~h}^{-1}$, conforme o método de cálculo, o que representa $20,7 \%$ da erosividade calculada para o período.

Outra evidência é a contabilização dos quatro eventos de maior erosividade no período (13,3\% dos eventos), que totalizaram 3.091,69 $\mathrm{MJ} \mathrm{mm} \mathrm{ha}^{-1}$ $\mathrm{h}^{-1}$, representando $47,2 \%$ da erosividade anual obtida. O período chuvoso, que

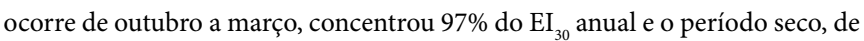
abril a setembro, os $3 \%$ restantes. A distribuição temporal do regime pluvial é característica da região, geralmente com verão chuvoso e inverno seco, e, consequentemente, da erosividade, que é diretamente dependente das precipitações mais intensas, sendo que vários pesquisadores, em diversas regiões do país, têm encontrado situação semelhante (DIAS; SILVA, 2003; SILVA et al., 2009;
BERTONI; LOMBARDI NETO, 2010; SILVA et al., 2010; AQUINO et al., 2012 AQUINO et al., 2013; AQUINO et al., 2014). Ainda que os valores obtidos para a erosividade estejam na mesma ordem de grandeza e inseridos nos intervalos propostos pelos autores citados, ressalta-se a importância da obtenção desse fator com dados observados na área estudada.

\section{Perdas de solo e água quantificadas nas parcelas experimentais}

No período de estudo foram realizadas 33 campanhas de monitoramento, cujos resultados totalizados para as perdas de solo e água nas parcelas experimentais constam na Tabela 3 .

Em relação ao CX (parcelas de 1 a 5), observam-se claramente os efeitos da classe de uso do solo, bem como da declividade, tanto para as taxas de perdas de solo (erosão hídrica) quanto para o deflúvio superficial. Em relação ao uso de solo, o efeito da cobertura sob mata foi muito expressivo. Na média, a taxa de perda de solo foi apenas $0,46 \%$ da observada para o CX exposto, salientando ainda que a declividade (D) média de $25 \%$ das áreas sob mata é superior à do solo exposto (12\%), o que, em geral, potencializa maiores perdas. Outro ponto a destacar foi o melhor desempenho da cobertura sob mata em relação à sob pastagem/campo, respectivamente, 0,46 e 1,6\% da taxa de perda de solo em solo exposto.

Corrêa, Moraes e Pinto (2015) apontam valores de tolerância de perda de solo (PS) para o CX exposto no estado de São Paulo de 4,15 t ha ${ }^{-1}$ ano $^{-1}$, com utilização de método proposto por Lombardi Neto e Bertoni (1975) e modificado por Bertol e Almeida (2000). Já Silva et al. (2009) apontam como referência para o limite de tolerância para os Cambissolos da região 5,60 tha-1 ano $^{-1}$, estimada segundo método proposto por Galindo e Margolis (1989). Para efeito de comparação, o valor aqui encontrado está acima dos limites apresentados, muito possivelmente refletindo o efeito de mineração a que foram submetidos anteriormente. Vale destacar, inicialmente, as diferenças nos valores encontrados na literatura para os limites de perdas toleráveis para o Cambissolo. Entretanto, mesmo para os limites toleráveis inferiores, o ideal seria tomar como limite a taxa de formação dos solos conforme preconizado pela FAO (2015).

Tabela 3 - Síntese do monitoramento da erosão hídrica nas parcelas instaladas na Sub-Bacia Hidrográfica do Córrego do Gigante - período de dez./2017 a dez./2018.

\begin{tabular}{|c|c|c|c|c|c|c|}
\hline Parcela & Classe solo & $\mathrm{LP}(\mathrm{mm})$ & IPS (t ha ${ }^{-1}$ ano $\left.^{-1}\right)$ & $\mathrm{PS}^{*}\left(\mathrm{t} \mathrm{ano}^{-1}\right)$ & $\mathrm{PS}^{* *}\left(\mathrm{t} \mathrm{ano}^{-1}\right)$ & $\mathrm{Df}(\mathrm{mm})$ \\
\hline P1 & $C X$ & 948,9 & 9,74 & 27,82 & 27,82 & 636 \\
\hline P2 & $C X$ & $1.150,1$ & 0,08 & 0,93 & 1,78 & 117,52 \\
\hline P3 & $C X$ & $1.140,5$ & 0,23 & 2,66 & 1,78 & 227,68 \\
\hline P4 & $C X$ & $1.239,8$ & 0,06 & 1,98 & \multirow{2}{*}{1,37} & 69,18 \\
\hline P5 & $c x$ & $1.132,4$ & 0,03 & 0,99 & & 19,36 \\
\hline P6 & LVA & 958,8 & 5,88 & 64,56 & 64,56 & 642 \\
\hline P7 & LVA & $1.339,8$ & 0,12 & 3,95 & \multirow{2}{*}{2,35} & 30,93 \\
\hline P8 & LVA & $1.345,0$ & 0,02 & 0,66 & & 22,26 \\
\hline P9 & LVA & $1.232,2$ & 0,20 & 6,88 & 6,88 & 94,31 \\
\hline P10 & LVA & $1.230,1$ & 0,08 & 3,88 & 3,88 & 19,37 \\
\hline Total & - & - & - & - & 108,63 & - \\
\hline
\end{tabular}

CX: Cambissolo Háplico; LVA: Latossolo Vermelho-Amarelo; LP: lâmina precipitada; IPS: taxa média de perda de solo; * perda de solo expandida para a área de ocorrência da associação representada na parcela experimental, junto à Sub-Bacia Hidrográfica do Córrego do Gigante (Tabela 1); **valor médio na classe de declividade; Df: deflúvio total. Fonte: elaboração própria. 
Em relação ao LVA (parcelas 6 a 10), também foram observados os mesmos comportamentos já apresentados para as taxas de PS e água para o CX, tanto para o efeito da cobertura vegetal quanto da declividade, embora com valores proporcionais distintos.

O valor da taxa de PS do LVA exposto foi de $5,88 \mathrm{tha}^{-1}$ ano $^{-1}$ e, tendo por base os limites de tolerância de perda indicados por Sparovek e Jong Van Lier (1997), Silva et al. (2005) e Silva et al. (2008), para os Latossolos expostos da ordem de 10 a $12 \mathrm{t} \mathrm{ha}^{-1}$ ano $^{-1}$, o valor encontrado neste estudo, para efeito de comparação, é considerado abaixo do limite indicado, porém, novamente, cabe aqui as ressalvas apresentadas pela FAO (2015) para a sustentabilidade ambiental dos solos, em que recomendam-se perdas próximas a zero ou, ainda, as taxas observadas nas matas nativas.

A taxa média de PS para o LVA sob mata (parcelas 7 e 8), da ordem de $0,07 \mathrm{t}$ ha $^{-1}$ ano $^{-1}$, é muito próxima da encontrada por Silva et al. (2011), que estimaram um valor de $0,067 \mathrm{t} \mathrm{ha}^{-1}$ ano $^{-1}$ de PS em parcela experimental sob floresta nativa com D de 42,4\%, na região do Vale do Rio Doce, sob LVA. Pires et al. (2006), em trabalho realizado em florestas de eucalipto na região centro-leste de Minas Gerais, estimaram PS de 0,109 $\mathrm{t} \mathrm{ha}^{-1} \mathrm{ano}^{-1}$ para o LVA.

Nas combinações campo/pastagem associadas ao LVA (parcelas 9 e 10), com declividades de 21 e $18 \%$, respectivamente, o valor médio observado para as taxas de PS foi de $0,140 \mathrm{t} \mathrm{ha}^{-1} \mathrm{ano}^{-1}$, que é inferior ao encontrado por Silva et al. (2011) para as mesmas combinações e condições de declividade, sendo este da ordem de $0,249 \mathrm{t} \mathrm{ha}^{-1}$ ano $^{-1}$, e próximo do valor encontrado por Pires et al. (2006) de $0,10 \mathrm{t} \mathrm{ha}^{-1}$ ano $^{-1}$ em parcela experimental, com $24,9 \%$ de declividade.

Os valores das taxas de PS de 5,88 e 9,74 $\mathrm{t} \mathrm{ha}^{-1}$ ano $^{-1}$, respectivamente, para o LVA e CX na condição de solo descoberto, sinalizam que o CX perdeu $65,6 \%$ a mais que o LVA, estando em consistência com a literatura técnico-científica, que aponta que os CXs são solos mais frágeis que os LVAs, Silva, Santos e Silva (2014), entre outros.

Trabalhos desenvolvidos por Carvalho et al. (2007), Silva et al. (2009), Martins et al. (2010), Almeida et al. (2016), que utilizaram parcelas experimentais com gradagem, ou aração com disco e gradagem, no sentido do declive do terreno, apresentaram valores maiores que os encontrados neste estudo para o CX e o LVA, muito possivelmente em função das intervenções promovidas na superfície do solo, que procuravam identificar o efeito dessas práticas sobre a erosão hídrica do solo.

Pode-se, portanto, com base nas referências apresentadas, inferir sobre a consistência dos resultados obtidos neste estudo, possibilitando, assim, o seu emprego no processo de calibração do modelo WEPP na sua versão encosta na área da Sub-Bacia Hidrográfica do Córrego do Gigante.

A aplicação dos resultados obtidos nas parcelas, para a área representada pelas suas combinações (174,3 ha), foi realizada calculando-se as perdas por uso para as respectivas áreas de ocorrência, conforme Tabela 1. Ressalta-se que, para a totalização das perdas, os valores utilizados para as parcelas 2 e 3; 4 e 5; e 7 e 8 foram as respectivas médias das duas parcelas por pertencerem, duas a duas, a uma mesma classe de D e, portanto, estarem inseridas em uma mesma área de ocorrência. Esse procedimento resultou em um valor de 108,63 $\mathrm{t} \mathrm{ano}^{-1}$, que correspondeu a uma taxa média ponderada de $0,623 \mathrm{tha}^{-1} \mathrm{ano}^{-1}$.

Devido à elevada relação entre as taxas de PS entre solos expostos e sob cobertura vegetal (Tabela 3), a participação dos solos expostos, nas PSs, é extremamente acentuada. Analisando-se separadamente, por classe de solo, constata-se que o CX exposto representou 6\% da área abrangida por essa classe de solo e contribuiu com $89,9 \%$ das perdas contabilizadas nessa classe de solo; já o LVA exposto, com $8,7 \%$ da área por ele abrangida, participou com $83,1 \%$ das perdas contabilizadas nessa classe de solo. No conjunto, as áreas de solos expostos totalizaram $7,9 \%$ da área abrangida e participaram com $84,4 \%$ do total das PSs, refletindo, assim, a importância da cobertura vegetal, sobretudo a existente na área em estudo, para a redução da degradação ambiental do solo.

Considerando-se ainda a área de 174,32 ha, contemplada pelas combinações de classe de solo e seus usos, o CX associado aos diferentes usos contemplados pelas parcelas totalizou uma área de 47,5 ha e uma perda de $30,96 \mathrm{t} \mathrm{ano}^{-1}$, resultando em uma perda média ponderada de $0,652 \mathrm{tha}^{-1} \mathrm{ano}^{-1}$. Já o LVA totalizou uma área de 126,82 ha e uma perda de 77,68 $\mathrm{t} \mathrm{ano}^{-1}$, representando uma perda média ponderada de $0,612 \mathrm{tha}^{-1} \mathrm{ano}^{-1}$. $\mathrm{O}$ cotejo entre essas médias mostra que as perdas do CX foram apenas 6,5\% maiores do que as do LVA, refletindo efeito mais significativo das coberturas vegetais no CX, pois, sem elas, o CX apresentou PS 65,6\% maior que o LVA, o que reforça a importância das boas práticas de uso do solo.

Os resultados apresentados na Tabela 3 permitem ainda identificar uma relação linear entre as taxas de perdas de solo por erosão hídrica (IPS) e o deflúvio superficial (Df), para cada classe de solo em separado, representadas pelas funções IPS $=0,0132^{\star} \mathrm{Df},\left(R^{2}=0,8325\right)$; e, IPS $=0,009^{*} \mathrm{Df},\left(\mathrm{R}^{2}=0,9814\right)$, respectivamente, para o CX e o LVA, sendo IPS em tha ${ }^{-1}$ ano $^{-1}$ e Df em mm, cujo coeficiente angular expressa a maior vulnerabilidade do $\mathrm{CX}$ ao deflúvio superficial direto em relação ao LVA.

Os efeitos das coberturas vegetais em relação às perdas de água (deflúvio superficial direto) seguiram o mesmo comportamento, evidenciando, assim, o efeito mais efetivo e positivo da cobertura sob mata, em relação a campo/ pastagem, no aumento da parcela de chuva que se infiltrou no solo, bem como na redução da erosão hídrica, o que ambientalmente é desejável. Ressalta-se, entretanto, que, embora as taxas de PS nas áreas sob cobertura vegetal tenham sido consideravelmente menores do que as observadas para solo exposto e estejam dentro das faixas encontradas na literatura, esses valores estão ainda muito superiores às taxas de formação dos solos, que deveriam ser, na realidade, $o$ referencial de sustentabilidade ambiental.

\section{Calibração do modelo Water Erosion Prediction Project}

Considerando-se os bancos de dados já inseridos, conforme descrito na metodologia, e que o simulador climático Cligen forneceu uma precipitação média anual de 1.537,2 mm, valor bem próximo do valor total precipitado na SubBacia Hidrográfica do Córrego do Gigante no período de estudo, ajustou-se o modelo WEPP tendo-se os resultados obtidos nas parcelas experimentais como referência para o procedimento de ajuste dos parâmetros do modelo.

Amorim (2003) realizou análises de sensibilidades para diversos parâmetros de entrada do modelo WEPP para as condições edafoclimáticas brasileiras, verificando que a erodibilidade entressulcos, a erodibilidade no sulco, a tensão cisalhante crítica e a condutividade hidráulica efetiva foram os parâmetros para os quais o WEPP apresentou maiores sensibilidades.

Cecílio et al. (2009) explicam a importância de aplicação do modelo WEPP com cautela diante das condições brasileiras, pois os parâmetros do modelo foram obtidos experimentalmente com base em características físicas dos solos norte-americanos.

A Tabela 4 apresenta, além dos valores das taxas de perdas de solo, observados e simulados para cada parcela experimental, a média ponderada das perdas anuais. 
Analisando-se, inicialmente, os resultados das PSs por classe de solo, constata-se que, para o CX, sobretudo para a condição de solo exposto, o WEPP subestimou os valores. Totalizando-se as estimativas para todas as combinações de uso, cuja área é de 47,5 ha, o valor foi de $27,57 \mathrm{t} \mathrm{ano}^{-1}$, que, ao ser relacionado com o observado nas parcelas $\left(30,96 \mathrm{t} \mathrm{ano}^{-1}\right)$, resulta no valor de 0,89 , que representa um desvio de $11 \%$ entre os resultados. Já para o LVA, cujas combinações com seus usos abrangem uma área de 126,82 ha, o total estimado pelo WEPP foi de 85,93 e o observado, de 77,67 t ano ${ }^{-1}$, resultando em uma relação de 1,11, que também significa um desvio de $11 \%$ entre os resultados, porém, neste caso, para mais.

Totalizando-se as perdas estimadas para as duas classes de solo obtém-se o valor de 113,67 $\mathrm{t} \mathrm{ano}^{-1}$, uma taxa média ponderada de PS de 0,651 $\mathrm{t} \mathrm{ha}^{-1} \mathrm{ano}^{-1}$, que, ao ser comparada com a observada nas parcelas $\left(0,623 \mathrm{t} \mathrm{ha}^{-1}\right.$ ano $\left.^{-1}\right)$, sinaliza um desvio de 4,5\% que permite avaliar como um ótimo ajuste do modelo WEPP. Amorim (2003) associa as superestimavas do modelo WEPP para as taxas de PS a prováveis inadequações das condições estudadas com as equações utilizadas pelo modelo para estimar alguns parâmetros, principalmente erodibilidade entressulcos, erodibilidade no sulco e condutividade hidráulica do solo, onde, subestimando-se a condutividade hidráulica do solo, geram-se mais Df e, consequentemente, maiores PSs.

Pode-se inferir que o bom ajuste obtido neste estudo pode estar associado ao uso dos valores da condutividade hidráulica efetiva (Ke), estimados para a área a partir de medições realizadas in situ, pois o modelo apresenta alta sensibilidade aos valores desse parâmetro.

\section{Simulação das perdas de solo pelo modelo Water Erosion Prediction Project}

Considerando-se os valores dos parâmetros calibrados para o modelo WEPP, aplicou-se o modelo WEPP (utilizando-se os valores dos parâmetros calibrados) para todas as interações entre classe de solo, classe de uso do solo (neste

Tabela 4 - Resultados obtidos na calibração do Water Erosion Prediction Project versão encosta para as perdas de solo.

\begin{tabular}{l|c|c|c|c|c}
\multirow{2}{*}{ Parcela } & Declividade & \multirow{2}{*}{ Solo } & Observado & \multicolumn{2}{|c}{ Estimado } \\
\cline { 5 - 6 } & Medida & & IPS $^{*}$ & IPS $^{* *}$ & PS $^{* *}$ \\
\cline { 5 - 6 } & 12 & CX & 9,74 & 5,15 & 14,71 \\
\hline P1 & 12 & CX & 0,08 & 0,24 & \multirow{2}{*}{2,78} \\
\hline P2 & 18 & CX & 0,23 & 0,24 & \\
\hline P3 & 28 & CX & 0,06 & 0,30 & \multirow{2}{*}{10,25} \\
\hline P4 & 22 & CX & 0,03 & 0,31 & \\
\hline P5 & 12 & LVA & 5,37 & 5,16 & 56,66 \\
\hline P6 & 28 & LVA & 0,12 & 0,31 & \multirow{2}{*}{10,20} \\
\hline P7 & 26 & LVA & 0,02 & 0,31 & \\
\hline P8 & 21 & LVA & 0,20 & 0,23 & 7,92 \\
\hline P9 & 18 & LVA & 0,08 & 0,23 & 11,16 \\
\hline P10 & - & - & $0,623^{* * *}$ & $0,651^{* * *}$ & 113,67 \\
\hline Total & & & & &
\end{tabular}

Fonte: elaboração própria.

CX: Cambissolo Háplico; LVA: Latossolo Vermelho-Amarelo; WEPP: Water Erosion Prediction Project; IPS: taxa de perda de solo; *observadas em campo; **estimadas pelo modelo WEPP; ***taxa média ponderada na área da Sub-Bacia Hidrográfica do Córrego do Gigante, observada e estimada. caso, incluindo reflorestamento) e classe de D (representada pela D média na classe, conforme descrito na metodologia), obtiveram-se, assim, as taxas de perdas de solo para cada uma das encostas simuladas (Tabela 5 - para o CX - e Tabela 6 - para o LVA) e, considerando-se as áreas de ocorrência de cada interação, estimaram-se as perdas correspondentes a essas áreas.

As interações do CX com as classes de uso e de D totalizaram 128,17 ha. Já as do LVA 202,11 ha, agrupadas, resultaram em 330,28 ha, significando que aproximadamente $93 \%$ da área de drenagem da Sub-Bacia Hidrográfica do Córrego do Gigante foi contemplada no processo de simulação.

A análise dos resultados para o CX exposto (Tabela 5) permite identificar a influência da D sobre a taxa de perda de solo (IPS), expressa pela função IPS $=0,249^{*} \mathrm{D}+2,951\left(\mathrm{R}^{2}=0,999\right)$, sendo IPS em $\mathrm{tha}^{-1} \mathrm{ano}^{-1} \mathrm{e} \mathrm{D}$ em percentual (\%), que sinaliza a vulnerabilidade do CX exposto à $\mathrm{D}$ do relevo, pois, a cada unidade acrescida a D, há aumento de $0,249 \mathrm{tha}^{-1}$ ano $^{-1}$ na PS. O CX exposto ocupa uma área de 11,46 ha na Sub-Bacia Hidrográfica do Córrego do Gigante, e as perdas estimadas totalizaram 107,15 $\mathrm{t} \mathrm{ano}^{-1}$, correspondendo a uma taxa média de $9,35 \mathrm{t} \mathrm{ha}^{-1}$ ano $^{-1}$, valor este muito próximo do apresentado nas parcelas experimentais $9,74 \mathrm{tha}^{-1} \mathrm{ano}^{-1}$.

Para o CX sob mata nativa, reflorestamento e campo/pastagem, as variações das PSs estimadas, em relação ao aumento da declividade, não se evidenciam, fato que está associado ao efeito positivo dessas coberturas vegetais em relação a interceptação da precipitação direta sobre a superfície do solo, aumento da infiltração e diminuição do Df direto. As taxas médias ponderadas para o CX sob uso de mata nativa, reflorestamento e campo/pastagem foram de 0,$249 ; 0,255 ;$ e 0,240 tha ${ }^{-1}$ ano $^{-1}$, respectivamente, e representam uma estimativa de redução média na taxa de erosão hídrica da ordem de $97,3 \%$, sendo que, nas parcelas experimentais, essas reduções foram 99,5 e 98,4\%, respectivamente, para mata e campo/pastagem.

Já a taxa média ponderada estimada para o CX foi da ordem de $1,06 \mathrm{t}$ ha $^{-1}$ ano $^{-1}$, destacando-se o efeito negativo do solo exposto na erosão hídrica do solo, pois, embora represente apenas $8,9 \%$ da área ocupada, participa com $78,9 \%$ das perdas estimadas.

Na Tabela 6 encontram-se os valores das taxas de PS estimados pelo WEPP para o LVA. Novamente, fica evidente a influência da D para o LVA exposto sobre a IPS, expressa pela função IPS $=0,197^{\star} \mathrm{D}+2,511\left(\mathrm{R}^{2}=0,999\right)$, sendo IPS em tha $\mathrm{t}^{-1}$ ano $^{-1} \mathrm{e} \mathrm{D}$ em percentual (\%), que sinaliza a vulnerabilidade do LVA exposto à $\mathrm{D}$ do relevo, pois, a cada unidade acrescida a $\mathrm{D}$, há aumento de 0,197 t ha ${ }^{-1}$ ano $^{-1}$ em PS. Na Sub-Bacia Hidrográfica do Córrego do Gigante, o LVA exposto ocupa uma área de 16,21 ha e as perdas estimadas totalizam $92,83 \mathrm{t} \mathrm{ano}^{-1}$, correspondendo a uma taxa média de 5,73 $\mathrm{tha}^{-1}$ ano $^{-1}$, valor este muito próximo do $5,88 \mathrm{t} \mathrm{ha}^{-1}$ ano $^{-1}$ apresentado nas parcelas experimentais.

Também para o LVA sob os usos de mata nativa, reflorestamento e campo/ pastagem não se evidencia, de forma consistente, o efeito do aumento da $\mathrm{D}$ sobre as PSs estimadas, como já analisado para o CX, reiterando o efeito positivo dessas coberturas vegetais. As taxas médias ponderadas para o LVA sob uso de mata nativa, reflorestamento e campo/pastagem foram de 0,$178 ; 0,184$; e $0,208 \mathrm{t} \mathrm{ha}^{-1}$ ano $^{-1}$, respectivamente, e representam uma estimativa de redução média na taxa de erosão hídrica da ordem de $96,7 \%$, sendo que, nas parcelas experimentais, esses valores foram entre 96,6 a $98,9 \%$, portanto muito próximos.

A taxa média ponderada de erosão hídrica para o LVA na Sub-Bacia Hidrográfica do Córrego do Gigante foi da ordem de 0,639 ha $^{-1}$ ano $^{-1}$. Destaca-se ainda que, mesmo considerando que a taxa estimada para o LVA exposto esteja abaixo dos limites de tolerância encontrados na literatura, e ainda o dato de 
representar apenas $8 \%$ da área por ele ocupada, sua participação com $71,9 \%$ das PSs estimada é altamente expressiva.

Assim, considerando-se que o CX ocupa uma área de 128,17 ha, com taxa média ponderada de PS de 1,06 $\mathrm{tha}^{-1} \mathrm{ano}^{-1}$, e o LVA ocupa uma área de 202,11 ha, com taxa média de $0,639 \mathrm{tha}^{-1}$ ano $^{-1}$, resulta uma taxa média ponderada de PS de 0,802 $\mathrm{t} \mathrm{ha}^{-1}$ ano $^{-1}$ para a área de 330,27 ha, representada na SubBacia Hidrográfica do Córrego do Gigante. Esse valor é superior ao obtido no processo de ajuste do WEPP, fato que se explica pela expansão da área abrangida (de 174,32 para 330,27 ha), que resultou em maior proporção de áreas com classes de declividades maiores, sobretudo para os solos expostos, os quais apresentam taxas mais elevadas de PS.

A Figura 4 sintetiza as Tabelas 5 e 6 de forma espacializada na Sub-Bacia Hidrográfica do Córrego do Gigante e as taxas médias ponderadas de PS (subtotais) para cada associação entre uso de solo e classe de solo, possibilitando, ainda, a visualização da distribuição espacial das classes e de seus usos.

Melo Neto et al. (2017) aplicaram a Revised Universal Soil Loss Equation (RUSLE) para estimar a vulnerabilidade dos solos da Sub-Bacia Hidrográfica do Córrego do Gigante à erosão hídrica, tendo obtido valores da ordem de $10 \mathrm{t}$ $\mathrm{ha}^{-1}$ ano $^{-1}$, superestimando, portanto, a taxa de perda desses solos.
Pelo menos dois fatores merecem ser apontados como determinantes dessa elevada diferença nos valores. O primeiro é que, embora a versão encosta seja a mais simples do WEPP, ela já incorpora o efeito de deposição de material erodido, o que não é contemplado pela RUSLE. O segundo fator é que no processo de ajuste do modelo, além da referência dos resultados das parcelas experimentais, as informações inseridas se aproximaram muito da realidade dos solos da Sub-Bacia Hidrográfica do Córrego do Gigante, minimizando a influência dos processos de estimativa dos atributos do solo pelas rotinas internas do WEPP.

Por último, considerando-se que na área da sub-bacia em estudo as práticas de recuperação dos solos degradados têm sido a regeneração da pastagem natural/plantio de pastagem e/ou reflorestamento, podem-se analisar dois cenários que decorrem da adoção dessas práticas. Ao se considerar as áreas de solo descoberto ocupadas por campo/pastagem, no caso do CX as perdas anuais reduziriam de 107,15 para 2,75 $\mathrm{t}$ ano $^{-1}$, representando redução de $97,33 \%$. Para o LVA, a redução seria de 92,83 para $3,47 \mathrm{t}_{\text {ano }}{ }^{-1}$, representando redução de $96,26 \%$ nas perdas. Ao se considerar as áreas de solo descoberto ocupadas por reflorestamento, o efeito seria praticamente idêntico. No CX, as perdas reduziriam de 107,15 para 2,89 $\mathrm{t} \mathrm{ano}^{-1}$, ou 97,3\%; no LVA, a redução seria de 92,83 para $3 \mathrm{t}_{\text {ano }}{ }^{-1}$, ou $96,77 \%$.

Tabela 5 - Taxas de perdas de solo para o Cambissolo Háplico, estimadas pelo modelo Water Erosion Prediction Project.

\begin{tabular}{|c|c|c|c|c|c|}
\hline$c x$ & Classe declividade (\%) & Declividade média na classe (\%) & IPS (t ha-1 ano-1) & Áreas (ha) & $\mathrm{PS}^{*}(\mathrm{t}$ ano-1) \\
\hline \multirow{5}{*}{ Solo exposto } & O a 3 & 2,97 & 3,55 & 0 & 0 \\
\hline & 3 a 8 & 6,10 & 4,52 & 0 & 0 \\
\hline & 8 a 20 & 16,83 & 7,28 & 2,86 & 20,82 \\
\hline & 20 a 45 & 28,27 & 9,96 & 8,47 & 84,36 \\
\hline & 45 a 75 & 49,28 & 15,17 & 0,13 & 1,97 \\
\hline Subtotal & & & $9,35^{\star \star}$ & 11,46 & 107,15 \\
\hline \multirow{5}{*}{ Mata nativa } & O a 3 & 1,40 & 0,15 & 0,19 & 0,03 \\
\hline & 3 a 8 & 5,82 & 0,28 & 0,39 & 0,11 \\
\hline & 8 a 20 & 15,83 & 0,26 & 5,30 & 1,38 \\
\hline & 20 a 45 & 31,16 & 0,25 & 23,08 & 5,77 \\
\hline & 45 a 75 & 56,52 & 0,24 & 7,32 & 1,76 \\
\hline Subtotal & & & $0,249^{* *}$ & 36,28 & 9,05 \\
\hline \multirow{5}{*}{ Reflorestamento } & O a 3 & 2,57 & 0,25 & 0,02 & 0,01 \\
\hline & 3 a 8 & 5,46 & 0,28 & 0,27 & 0,08 \\
\hline & 8 a 20 & 16,30 & 0,26 & 4,49 & 1,17 \\
\hline & 20 a 45 & 28,40 & 0,25 & 9,84 & 2,46 \\
\hline & 45 a 75 & 56,00 & 0,25 & 0,70 & 0,18 \\
\hline Subtotal & & & $0,255^{\star *}$ & 15,32 & 3,90 \\
\hline \multirow{5}{*}{ Campo/pastagem } & O a 3 & 1,58 & 0,21 & 0,07 & 0,01 \\
\hline & 3 a 8 & 5,77 & 0,25 & 0,45 & 0,11 \\
\hline & 8 a 20 & 16,36 & 0,24 & 11,58 & 2,78 \\
\hline & 20 a 45 & 29,23 & 0,24 & 45,93 & 11,02 \\
\hline & 45 a 75 & 53,23 & 0,24 & 7,08 & 1,70 \\
\hline Subtotal & & & $0,240^{* *}$ & 65,11 & 15,62 \\
\hline Total & \multicolumn{3}{|c|}{$1,06^{* \star *}$} & 128,17 & 135,71 \\
\hline
\end{tabular}

CX: Cambissolo Háplico; WEPP: Water Erosion Prediction Project; *valor da perda na área de abrangência de cada interação; **taxa média ponderada do uso de solo; ***taxa média ponderada do solo na Sub-Bacia Hidrográfica do Córrego do Gigante.

Fonte: elaboração própria. 
Relativizando para a área como um todo, esses dois cenários resultariam em uma redução da taxa média ponderada de 0,802 para $0,215 \mathrm{t} \mathrm{ha}^{-1} \mathrm{ano}^{-1}$ para a opção campo/pastagem e de 0,802 para $0,214 \mathrm{t} \mathrm{ha}^{-1}$ ano $^{-1}$ para a opção reflorestamento, representando, assim, uma redução nas PSs da ordem de 73\%, o que, em termos relativos, é substancial e sinaliza um potencial de manejo bem factível, pois são práticas já empregadas na região.

\section{CONCLUSÕES}

As precipitações ocorridas no período de estudo apresentaram elevados graus de erosividade e de concentração, pois 57,3\% da lâmina precipitada foi erosiva e quatro dos eventos mais erosivos corresponderam a 47,2\% da erosividade anual estimada.

Os resultados obtidos nas parcelas experimentais de monitoramento de perda de solo e água evidenciaram diferenças entre o CX e o LVA, no tocante às taxas de PS, bem como o positivo efeito das coberturas vegetais existentes na redução dos valores dessas taxas.

O modelo WEPP, na sua versão encosta, ajustou-se aos resultados obtidos experimentalmente, estimando a taxa anual de PS com diferença de $4,8 \%$ a mais, podendo-se atribuir essa performance ao uso dos valores de condutividade hidráulica efetiva obtida a partir de medições in situ.

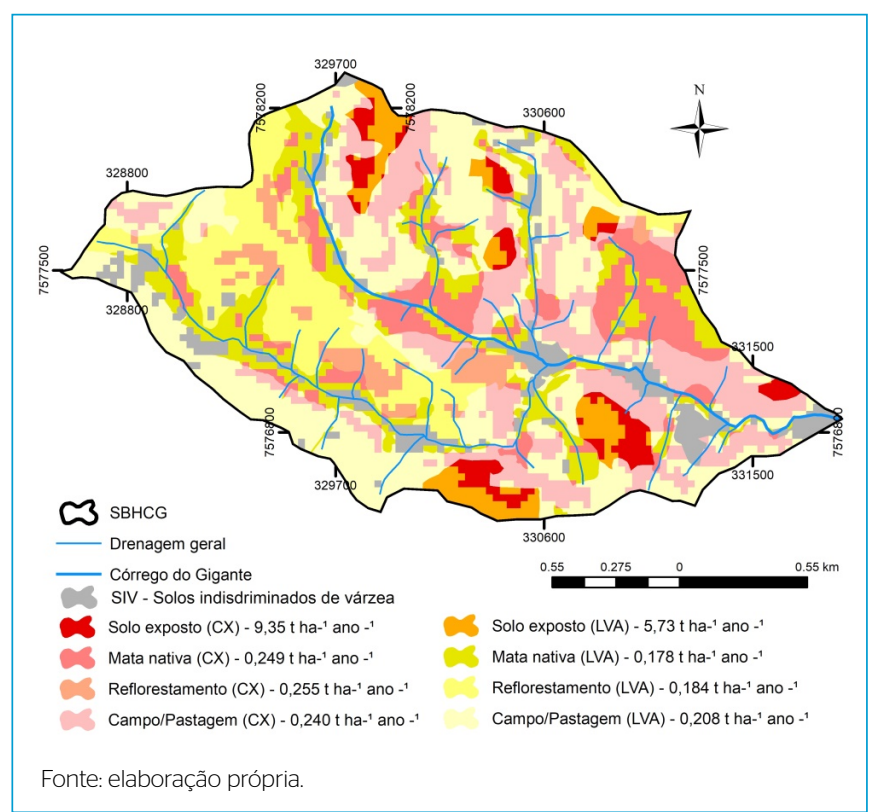

Figura 4 - Espacialização das taxas de perda de solo (nas classes de uso do solo) na Sub-Bacia Hidrográfica do Córrego do Gigante.

Tabela 6 - Taxas de perdas de solo para o Latossolo Vermelho-Amarelo, estimadas pelo modelo Water Erosion Prediction Project.

\begin{tabular}{|c|c|c|c|c|c|}
\hline LVA & Classe declividade (\%) & Declividade média na classe (\%) & IPS (t ha ${ }^{-1}$ ano $\left.^{-1}\right)$ & Áreas (ha) & $\mathrm{PS}^{*}\left(\mathrm{t}\right.$ ano $\left.{ }^{-1}\right)$ \\
\hline \multirow{4}{*}{ Solo exposto } & Oa3 & 2,26 & 2,78 & 0,14 & 0,39 \\
\hline & 3 a 8 & 5,79 & 3,68 & 1,62 & 5,96 \\
\hline & 20 a 45 & 26,11 & 7,72 & 3,45 & 26,62 \\
\hline & 45 a 75 & 48,57 & 12 & 0,03 & 0,38 \\
\hline \multirow{4}{*}{ Mata nativa } & 3 a 8 & 5,87 & 0,18 & 3,37 & 0,60 \\
\hline & 8 a 20 & 14,64 & 0,18 & 17,58 & 3,20 \\
\hline & 20 a 45 & 28,89 & 0,17 & 22,44 & 3,82 \\
\hline & 45 a 75 & 54,22 & 0,24 & 2,15 & 0,52 \\
\hline \multirow[t]{3}{*}{ Reflorestamento } & 8 a 20 & 13,84 & 0,19 & 22,05 & 4,12 \\
\hline & 20 a 45 & 26,26 & 0,17 & 10,62 & 1,84 \\
\hline & 45 a 75 & 53,82 & 0,25 & 0,37 & 0,09 \\
\hline Subtotal & & & $0,184^{* *}$ & 42,71 & 7,86 \\
\hline \multirow{5}{*}{ Campo/pastagem } & Oa 3 & 1,8 & 0,18 & 2,09 & 0,38 \\
\hline & 3 a 8 & 5,88 & 0,21 & 10,13 & 2,17 \\
\hline & 8 a 20 & 14,38 & 0,22 & 48,51 & 10,43 \\
\hline & 20 a 45 & 26,43 & 0,20 & 34,43 & 6,82 \\
\hline & 45 a 75 & 53,04 & 0,19 & 1,56 & 0,30 \\
\hline Subtotal & & & $0,208^{* *}$ & 96,72 & 20,1 \\
\hline
\end{tabular}

LVA: Latossolo Vermelho-Amarelo; IPS: taxa de perda de solo; PS: perda de solo; WEPP: Water Erosion Prediction Project; *valor da perda na área de abrangência de cada interação; **taxa média ponderada na classe de uso de solo; ***taxa média ponderada de perda do solo na Sub-Bacia Hidrográfica do Córrego do Gigante.

Fonte: elaboração própria. 
A simulação da erosão hídrica do solo pelo modelo WEPP para a Sub-Bacia do Córrego do Gigante evidenciou a diferença das taxas de PS entre o CX e o LVA, o efeito da D no aumento das taxas de PS na condição de solo exposto e o elevado efeito positivo e atenuador da erosão hídrica da cobertura vegetal.

A implantação de cobertura sob a forma de campo/pastagem e/ou reflorestamento nas áreas de solo descoberto sinaliza redução potencial de perda de solo bastante significativa ( $73 \%$ em média).

\section{AGRADECIMENTOS}

Os autores agradecem a Universidade Federal de Alfenas (UNIFAL-MG); ao DME Energética S.A. - Poços de Caldas e Mineração Curimbaba.

\section{CONTRIBUIÇõES DOS AUTORES}

Ferreira, A. M.: Conceituação, Curadoria de Dados, Análise Formal, Investigação, Metodologia, Escrita - Primeira Redação, Escrita - Revisão e Edição. Silva, A. M.: Conceituação, Curadoria de Dados, Análise Formal, Investigação, Metodologia, Administração de Projeto, Obtenção de Financiamento, Recursos, Supervisão, Escrita - Primeira Redação, Escrita - Revisão e Edição. Passos, C. A.: Investigação, Metodologia, Validação, Escrita - Primeira Redação. Valentino, C. H.: Investigação, Metodologia, Validação, Escrita - Primeira Redação. Gonçalves, F. A.: Conceituação, Curadoria de Dados, Análise Formal, Investigação, Supervisão, Escrita - Revisão e Edição. Menezes, P. H. J.: Conceituação, Curadoria de Dados, Análise Formal, Metodologia, Recursos, Investigação, Supervisão, Escrita — Revisão e Edição.

\section{REFERÊNCIAS}

ALEXANDER, E.B. Rates of soil formation: implications for soil loss tolerance. Soil Science, v. 145, n. 1, p. 37-45, 1988.

ALMEIDA, W.S.; CARVALHO, D.F.; PANACHUKI, E.; VALIM, W.C.; RODRIGUES, S.A.; VARELLA, C.A.A. Erosão hídrica em diferentes sistemas de cultivo e níveis de cobertura do solo. Pesquisa Agropecuária Brasileira, Brasília, v. 51, n. 9, p. 1110-1119, 2016. https://doi.org/10.1590/s0100-204×2016000900010

AMORIM, R.S.S. Avaliação dos modelos de predição da erosão hídrica USLE, RUSLE e WEPP para condições edafoclimáticas brasileiras. 123f. Tese (Doutorado em Engenharia Agrícola) - Universidade Federal de Viçosa, Viçosa, 2003.

AQUINO, R.F.; SILVA, M.L.N.; FREITAS, D.A.F.; CURI, N.; AVANZI, J.C. Soil losses from typic cambisols and red latosol as related to three erosive rainfall patterns. Revista Brasileira de Ciência do Solo, v. 37, n. 1, p. 213-220, 2013. https://doi.org/10.1590/S0100-06832013000100022

AQUINO, R.F.; SILVA, M.L.N.; FREITAS, D.A.F.; CURI, N.; MELLO, C.R.; AVANZI, J.C. Erosividade das chuvas e tempo de recorrência para Lavras, Minas Gerais. Revista Ceres, v. 61, n. 1, p. 9-16, 2014. https://doi.org/10.1590/S0034737X2014000100002

AQUINO, R.F.; SILVA, M.L.N.; FREITAS, D.A.F.; CURI, N.; MELLO, C.R.; AVANZI, J.C. Spatial variability of the rainfall erosivity in southern region of Minas Gerais state, Brazil. Ciência e Agrotecnologia, v. 36, n. 5, p. 533-542, 2012. https://doi.org/10.1590/S1413-70542012000500006

BARROSO, D.G.; SILVA, M.L.N. Poluição e Conservação de Recursos naturais: solo e água. Informe Agropecuário, v. 176, n. 16, p. 17-24, 1992.

BATISTA, P.V.G. Modelagem da erosão hídrica e métodos de interpolação de batimetria fluvial na bacia do Alto Rio Grande (MG). 107f. Tese (Doutorado) - Programa de Pós-Graduação em Ciência do Solo, Universidade Federal de Lavras, Lavras, 2016.

BERTOL, I: ALMEIDA, J.A. Tolerância de perda de solo por erosão para os principais solos do Estado de Santa Catarina. Revista Brasileira de Ciência do Solo, v. 24, n. 3 , p. 657-668, 2000. https://doi.org/101590/S0100-06832000000300018

BERTONI, J.; LOMBARDI NETO, F. Conservação do solo. Piracicaba: Ícone, 2010. $355 p$
CÂNDIDO, B.M.; SILVA, M.L.N.; CURI, N.; BATISTA, P.V.G. Erosão Hídrica PósPlantio em Florestas de Eucalipto na Bacia do Rio Paraná, no Leste do Mato Grosso do Sul. Revista Brasileira de Ciência do Solo, Viçosa, v. 38, n. 5, p. 1565-1575, 2014. https://doi.org/10.1590/S0100-06832014000500022

CARVALHO, R.; SILVA, M.L.N.; AVANZI, J.C.; CURI, N.; SOUZA, F.S. Erosão hídrica em Latossolo Vermelho sob diversos sistemas de manejo do cafeeiro no sul de Minas Gerais. Ciência e Agrotecnologia, v. 31, n. 6, p. 1679 1687, 2007. https://doi.org/10.1590/S1413-70542007000600012

CECÍLIO, R.A.; RODRIGUEZ, R.G.; BAENA, L.G.N.; OLIVEIRA, F.G.; PRUSKI, F.F. Aplicação dos modelos RUSLE e WEPP para a estimativa da erosão hídrica em microbacia hidrográfica de Viçosa (MG). Revista Verde, v. 4, n. 2, p. 39-45, 2009.

CHAVES, H.M.L. Modelagem matemática da erosão hídrica: passado, presente e futuro. In: ALVAREZ, V.H.; FONTES, L.E.; FONTES, M.P.F. (org.). O solo nos grandes domínios morfoclimáticos do Brasil e o desenvolvimento sustentado. Viçosa: SBCS, UFV, DPS, 1996. p. 731-750.

CORREAA, E.A.; MORAES, I.C.; PINTO, S.A.F. Estimativa da Erodibilidade e Tolerância de Perdas de Solo na Região do Centro Leste Paulista. Geociências, v. 34, n. 4, p. 848-860, 2015.

DEMARCHI, J.C.; ZIMBACK, C.R.L. Mapeamento, erodibilidade e tolerância de perda de solo na sub-bacia do Ribeirão das Perobas. Energia na Agricultura, v. 29, n. 2, p. 102-114, 2014. https://doi.org/10.17224/ EnergAgric.2O14v29n2p102-114

DE MARIA, I.C. Cálculo da erosividade da chuva. In: LOMBARDI NETO, F.; CASTRO, O.M.; DECHEN, S.C.F; VIEIRA, S.R; MARIA, I.C. Manual de programas de processamento de dados de campo e de laboratório para fins de experimentação em conservação do solo. Campinas: IACSCS, 1994.

DIAS, A.S.; SILVA, J.R.C. A erosividade das chuvas em Fortaleza (CE): I - distribuição, probabilidade de ocorrência e período de retorno - 1a aproximação. Revista Brasileira de Ciência do Solo, v. 27, n. 2, p. 335-345, 2003. https://doi.org/101590/S0100-06832003000200013

DOTTERWEICH, M. The history of human-induced soil erosion: Geomorphic legacies, early descriptions and research, and the development of soil conservation-A global synopsis. Geomorphology, v. 201, p. 1-34, 2013. https://doi.org/10.1016/j.geomorph.2013.07.021 
ELLERT, R. Contribuição à Geologia do Maciço Alcalino de Poços de Caldas. Boletim da Faculdade de Filosofia Ciências e Letras, v. 237, n. 18, p. 5-60, 1959. https://doi.org/10.11606/issn.2526-3862.bffcluspgeologia.1959.121851

EMPRESA BRASILEIRA DE PESQUISA AGROPECUÁRIA (EMBRAPA). Centro de Pesquisas de Solos. Sistema brasileiro de classificação de solos. 2. ed. Brasília: Embrapa Produção de Informação; Rio de Janeiro: Embrapa Solos, 2006.

FLANAGAN, D.C.; NEARING, M.A. (org.). USDA. Water erosion prediction project - WEPP. West Laffayete: USDA-ARS-MWA-SWCS, 1995. (Technical Documentation, NSERL, Report n. 10).

FOOD AND AGRICULTURAL ORGANIZATION (FAO). Soil erosion: the greatest challenge to sustainable soil management. Roma: FAO, 2019.100 p.

FOOD AND AGRICULTURAL ORGANIZATION (FAO). Status of the world's soil resources: main report. Roma: FAO, 2015.

FOSTER, G.R.; MCCOOL, D.K.; RENARD, K.G.; MOLDENHAUER, W.C. Conversion of the universal soil loss equation to SI metric units. Journal of Soil Water Conservation, v. 36, n. 6, p. 355-359, 1981.

GALINDO, I.C.L.; MARGOLIS, E. Tolerância de perdas por erosão para solos do Estado de Pernambuco. Revista Brasileira de Ciência do Solo, v. 13, p. 95-100, 1989.

GONÇALVES, F.A. Validação do Modelo WEPP na Predição de Erosão Hidrica para Condição Edafoclimática da Região de Viçosa-MG. 116f. Tese (Doutorado em Engenharia Agrícola) - Universidade Federal de Viçosa, Viçosa, 2008.

GONÇALVES, F.A.; SILVA, D.D.; PRUSKI, F.F.; CARVALHO, D.F.; CRUZ, E.S. Índices e espacialização da erosividade das chuvas para o Estado do Rio de Janeiro. Revista Brasileira de Engenharia Agrícola e Ambiental, v. 10, n. 2. p. 269-276, 2006. https://doi.org/10.1590/S1415-43662006000200004

HIGGIT, D.L. Soil erosion and soil problems. Progress in Physical Geography, v. 15, n. 1, p. 91-100, 1991. https://doi.org/10.1177\%2F030913339101500108

HU, L.; FLANAGAN, D.C. Towards new-generation soil erosion modeling: Building a unified omnivorous model. Journal of Soil Water Conservation, v. 68, n. 4, p. 100-103, 2013. https://doi.org/10.2489/jswc.68.4.100A

LANE, L.J.; RENARD, K.G.; FOSTER, G.R.; LAFLEN, J.M. Development and application of modern soil erosion prediction technology. Australian Journal of Soil Research, v. 30, n. 6, p. 893-912, 1992. https://doi.org/10.1071/SR9920893

LAFLEN, J.M.; LANE, L.J.; FOSTER, G.R. The water erosion prediction project - a new generation of erosion prediction technology. Journal of Soil and Water Conservation, v. 46, n. 1, p. 34-38, 1991.

LI, L.; DU, S.; WU, L.; LIU, G. An overview of soil loss tolerance. Catena, v. 78, n. 2, p. 93-99, 2009.

LOMBARDI NETO, F; BERTONI, J. Tolerância de perdas de terras para solos do Estado de São Paulo. Boletim Técnico, 1975.

MARTINS, S.G.; SILVA, M.L.N.; AVANZI, J.C.; CURI, N.; FONSECA, S. Fator cobertura e manejo do solo e perdas de solo eágua em cultivo de eucalipto e em Mata Atlântica nos Tabuleiros Costeiros do Estado do Espírito Santo. Scientia Forestalis, v. 38, n. 87, p. 517-526, 2010.

MELLO, C.R.; SÁ, M.A.C.; CURI, N.; MELLO, J.M.; VIOLA, M.R.; SILVA, A.M. Erosividade mensal e anual da chuva no Estado de Minas Gerais. Pesquisa Agropecuária Brasileira, v. 42, n. 4, p. 537-545, 2007. https://doi.org/10.1590/ S0100-204X2007000400012
MELO NETO, J.O. Análise de sensibilidade escalar do modelo hidrológico SWAT. Dissertação (Mestrado em Sistemas Agrícolas) - Universidade Federal de Lavras, Lavras, 2012.

MELO NETO, J.O; SILVA, A.M.; FERREIRA, A.M.; MENEZES, P.H.B.J. GUIMARAES, D.V. Vulnerabilidade dos solos à erosão em bacia hidrográfica minerada no sul de Minas Gerais. In: CONGRESSO INTERNACIONAL DE HIDROSSEDIMENTOLOGIA, 2., 2017. Anais [...]. Rio de Janeiro: Interciência, 2017. v. 1.

MORAES, F.T. Zoneamento geomanbiental do Planalto de Poços de Caldas, MG/SP a partir de análise fisiográfica e pedoestratigráfica. 173f. Tese (Doutorado em Geociências) - Instituto de Geociências e Ciências Exatas, Universidade Estadual Paulista "Júlio de Mesquita Filho", Rio Claro, 2007.

MORAES, F.T;; JIMÉNEZ-RUEDA, J.R. Fisiografia da região do planalto de Poços de Caldas, MG/SP. Revista Brasileira de Geociências, v. 38, n. 1, p. 196208, 2008.

PEREIRA, T.T.C.; KER, J.C.; SCHAEFER, C.E.G.R.; BARROS, N.F.; NEVES, J.C.L.; ALMEIDA, C.C. Gênese de latossolos e Cambissolos desenvolvidos de rochas pelíticas do grupo Bambuí - Minas Gerais. Revista Brasileira de Ciência do Solo, v. 34, n. 4, p. 1283-1295, 2010. https://doi.org/10.1590/SO10006832010000400026

PIRES, L.S.; SILVA, M.L.N.; CURI, N.; LEITE, F.P.; BRITO, L.F. Erosão hídrica pósplantio em florestas de eucalipto na região centro-leste de Minas Gerais. Pesquisa Agropecuária Brasileira, v. 41, n. 4, p. 687-695, 2006. https://doi. org/10.1590/S0100-204X2006000400021

PRUSKI, F.F. Conservação do solo e água: práticas mecânicas para o controle de erosão hídrica. 2. ed. Viçosa: Editora UFV, 2013.

PURCINO, M.D. Espacialização dos parâmetros físico-hídricos do solo e associação com a vulnerabilidade à erosão hídrica em dois ambientes antropizados do Ribeirão do Cipó. 131f. Dissertação (Mestrado em Ciência e Engenharia Ambiental) - Universidade Federal de Alfenas, Poços de Caldas, 2017.

RAMON, R.; MINELLA, J.P.G.; MERTEN, G.H.; BARROS, C.A.P.; CANALE, T. Kinetic energy estimation by rainfall intensity and its usefulness in predicting hydrosedimentological variables in a small rural catchment in southern Brazil. Catena, v. 148, parte 2, p. 176-184, 2017. https://doi. org/10.1016/j.catena.2016.07.015

REIS, C.G.D. Modelagem dos parâmetros da curva de retenção de água no solo para a Sub-Bacia Hidrográficado córrego gigante. 39f. Trabalho de Conclusão de Curso (Graduação em Engenharia Ambiental) - Universidade Federal de Alfenas, Poços de Caldas, 2017.

SILVA, A.M.; MELLO, C.R.; CURI, N.; OLIVEIRA, P.M. Simulação da variabilidade espacial da erosão hídrica em uma sub-Sub-Bacia Hidrográfica de latossolos no Sul de Minas Gerais. Revista Brasileira de Ciência do Solo, v. 32, n. 5, p. 2125-2134, 2008. https://doi.org/10.1590/ S0100-06832008000500033

SILVA, A.M.; SILVA, M.L.N.; CURI, N.; AVANZI, J.C.; FERREIRA, M.M. Erosividade da chuva e erodibilidade de Cambissolo e Latossolo na região de Lavras, Sul de Minas Gerais. Revista Brasileira de Ciência do Solo, v. 33, n. 6, p. 18111820, 2009. https://doi.org/10.1590/S0100-06832009000600029

SILVA, A.M.; SILVA, M.L.N.; CURI, N.; LIMA, J.M.; AVANZI, J.C.; FERREIRA, M.M. Perdas de solo, água, nutrientes e carbono orgânico em cambissolo e latossolo sob chuva natural. Pesquisa Agropecuária Brasileira, v. 40, n. 12, p. 1223-1230, 2005. https://doi.org/10.1590/SO100-204X2005001200010 
SILVA, L.A. Deflúvio Superficial em Minas Gerais - caracterização e associação com fatores físicos e ambientais. 121f. Tese (Doutorado em Recursos Hídricos em Sistemas Agrícolas) - Universidade Federal de Lavras, Lavras, 2014.

SILVA, M.A.; SILVA, M.L.N.; CURI, N.; AVANZI, J.C.; LEITE, F.P. Sistemas de manejo em plantios florestais de eucalipto e perdas de solo e água na região do Vale do Rio Roce, MG. Ciência Florestal, Santa Maria, v. 21, n. 4, p. 765-776, 2011. https://doi.org/10.5902/198050984520

SILVA, M.A.; SILVA, M.L.N.; CURI, N.; SANTOS, G.R.; MARQUES, J.J.G.S.; MENEZES, M.D.; LEITE, F.P. Avaliação e espacialização da erosividade da chuva no Vale do Rio Doce, região centro-leste do Estado de Minas Gerais. Revista Brasileira de Ciência do Solo, v. 34, n. 4, p. 1029-1039, 2010. https:// doi.org/10.1590/S0100-06832010000400003

SILVA, R.M.; SANTOS, C.A.G.; SILVA, A.M. Predicting soil erosion and sediment yield in the Tapacurá catchment, Brazil. Journal of Urban and Environmental Engineering, v. 8, n. 1, p. 75-82, 2014.

SOIL SCIENCE SOCIETY OF AMERICA. Glossary of soil science terms. Madison: Soil Science Society of America, 2008.

SPAROVEK, G.; JONG VAN LIER, Q. Definition of tolerable soil conservation values. Revista Brasileira de Ciência do Solo, v. 21, n. 3, p. 467-471, 1997. https://doi.org/10.1590/S0100-06831997000300016

STROOSNIJDER, L. Measurement of erosion: is it possible? Catena, v. 64, n. 2-3, p. 162-173, 2005. https://doi.org/10.1016/j.catena.2005.08.004
TINÓS, T.; FERREIRA, M.; RIEDEL, P.; ZAINE, J. Aplicação e avaliação de metodologia de classificação automática de padrões de formas semelhantes do relevo. Revista Brasileira de Geomorfologia, v. 15, n. 3, p. 353-370, 2014. https://doi.org/10.20502/rbg.v15i3.455

TOY, T.J.; FOSTER, G.R.; RENARD, K.G. Soil erosion: processes, prediction, measurement and control. Nova York: John \& Sons, 2002. 338 p.

UNITED STATE DEPARTMENT OF AGRICULTURAL (USDA). Water erosion prediction project - WEPP. West Laffayete: USDA, 1995. (Technical documentation, NSERL, Report n. 10).

UNIVERSIDADE FEDERAL DE VIÇOSA (UFV); FUNDAÇÃO CENTRO TECNOLOGICO DE MINAS GERAIS (CETEC-MG); UNIVERSIDADE FEDERAL DE LAVRAS (UFLA); FUNDAÇÃO ESTADUAL DO MEIO AMBIENTE (FEAM). Mapa de Solos do Estado de Minas Gerais: legenda expandida. Belo Horizonte: Fundação Estadual do Meio Ambiente, 2010. 49 p.

WAGNER, C.S.; MASSAMBANI, O. Análise da relação intensidade de chuvaenergia cinética de Wischmeier \& Smith e sua aplicabilidade à região de São Paulo. Revista Brasileira de Ciência do Solo, Campinas, v. 12, n. 3, p. 197 203, 1988.

WISCHMEIER, W.H.; SMITH, D.D. Predicting rainfall erosion losses: a guide to conservation planning. Estados Unidos: U.S. Department of Agriculture, 1978. 58 p. (Agriculture Handbook, n. 537). 